\title{
DESERTIFICAÇÃO: ANÁLISE MULTITEMPORAL DA TEMPERATURA DE SUPERFÍCIE RELACIONADA AO ÍNDICE TOPOGRÁFICO DE UMIDADE.
}

\author{
Lucas Amorim Fernandes ${ }^{1}$; Elane Fiúza Borges ${ }^{2}$ \\ 1. Bolsista PIBIC/CNPq, Graduando do Bacharelado em Geografia, Universidade Estadual de Feira de Santana, e-mail: \\ lucas.amorimfernandes@gmail.com \\ 2. Orientadora, Departamento de Ciências Humanas e Filosofia, Universidade Estadual de Feira de Santana, e-mail: \\ elaneborges@gmail.com
}

PALAVRAS-CHAVE: Desertificação; Caatinga; Geotecnologias.

\section{INTRODUÇÃO}

O processo de desertificação é considerado um dos mais severos do planeta devido aos sérios problemas ecológicos e ambientais desencadeados por esse fenômeno. A desertificação é um "processo de degradação das terras em zonas áridas, semiáridas e subúmidas secas, resultantes de variações climáticas e atividades humanas", associada à perda de biodiversidade e ao aumento da temperatura de superfície de albedo (CHARRUA, 2014).

Um dos principais fatores que influencia na temperatura, de acordo com Santos (2010), é a topografia, devido ao aquecimento diferenciado do sol na superfície. Além disso, as diferenças de altitude, provocadas pelas diferenças topográficas do terreno, ao provocar alterações no volume de precipitação, também influenciam na temperatura de superfície (SANTOS, 2010). As diversas características topográficas do relevo têm grande influência nos corpos hídricos. Em relevos de topografia mais acidentada com maior declividade e solos muito rasos a água é encontrada em menor quantidade, pois escoa rapidamente para as áreas mais baixas do terreno, porém relevos de declividades mais suavizadas e áreas mais aplainadas promovem maior capacidade de armazenamento da água. O Índice Topográfico de Umidade (TWI) está relacionado a distribuição das zonas de saturação de água superficial e da água no solo. Dessa forma, com base no MDT, o índice topográfico de umidade estima balanços entre o acúmulo de água e a capacidade de drenagem em escala local (HANCOCK et al., 2010).

De acordo com Coelho (2013) nos últimos anos o Sensoriamento Remoto vem ganhando espaço no meio acadêmico, surgiu como uma alternativa por meio de escalas regionais, tendo como possibilidade determinar parâmetros, como temperatura e albedo de superfície (Angelini et al., 2015). Desse modo, objetiva-se fazer a correlação da temperatura de superfície com o índice topográfico de umidade e associar ao processo de Desertificação.

\section{PROCEDIMENTOS METODOLÓGICOS}

A pesquisa está relacionada ao Polo Desertificação de Jeremoabo-BA, o qual inclui os municípios de Antas, Canudos, Chorrochó, Coronel João Sá, Glória, Jeremoabo, Macururé, Novo Triunfo, Paulo Afonso, Pedro Alexandre, Rodelas, Santa Brígida e Uauá (Figura 1). O bioma predominante em todo o Polo é a Caatinga; o clima da região, segundo a caracterização de Koppen, é semiárido predominantemente seco, com temperatura média de $27^{\circ} \mathrm{C}$ e baixa pluviosidade entre 250 e $800 \mathrm{~mm}$ anuais. 


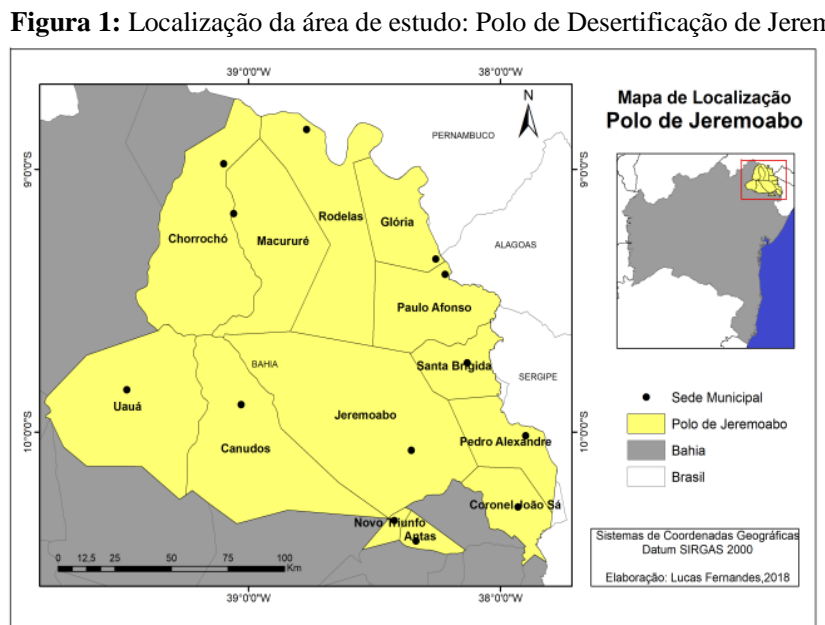

Fonte: Elaboração do autor.

Para o desenvolvimento dessa pesquisa foram utilizados os seguintes materiais:

$>\quad$ MDT (Modelo Digital de Terreno) de 30 metros, disponibilizado pelo TOPODATA do USGS (Science for a Changing World);

Softwares de geotecnologias: ARCGIS 10.3, QGIS 3.0; Girona; e, SAGA GIS 2.3;

Mapa de Solos do Polo de Jeremoabo (EMBRAPA, 2011);

Dados do sensor MODIS do produto MOD11A2.

$>\quad$ Dados do sensor MODIS do produto MOD11A2. Polo de Jeremoabo, com resolução espacial de $1 \mathrm{~km}$;

$>\quad$ Mapa do Índice Topográfico de Umidade do Polo de Jeremoabo, com resolução espacial de $30 \mathrm{~m}$.

Inicialmente foi realizada a revisão bibliográfica relacionada aos temas estudados: Desertificação, Temperatura de Superfície (TST), MDE (Modelo Digital de Elevação), Índice Topográfico de Umidade (TWI), Sensoriamento Remoto e Sensor MODIS. Foi realizada a correlação entre o TWI e o mapa de Temperatura de Superfície entre os anos 2000 a 2016 por meio de gráficos de correlação de pontos a partir dos valores extraídos de 500 pontos aleatórios (ferramenta Extract Values To Points) nas duas variáveis, utilizando método Random no ARCGIS 10.3. O mapa do Índice Topográfico de Umidade foi gerado a partir da variável de declividade nos softwares QGIS 3.0; Girona e SAGA GIS 2.3 por meio da ferramenta Saga Wetness Index. A temperatura de superfície (TST) no Polo de Jeremoabo foi estimada por meio de imagens termais, disponibilizadas pelo sensor MODIS (resolução temporal de 1-2 dias) a partir do produto MOD11A2 o qual utiliza o algoritmo LST para realizar cálculos de TST, fornecendo dados georreferenciados e corrigidos gerando dessa forma, mapas de temperatura de superfície com resolução espacial de $1 \mathrm{~km}$ para uma série temporal de 17 anos (2000-2016) para o Polo de Jeremoabo e adição de 500 pontos pelo método Random e a extração de seus valores utilizando a ferramenta Extract Values To Points no ARCMAP 10.3.

\section{RESULTADOS E DISCUSSÃO}

Como primeiro resultado dessa pesquisa têm-se os mapas de temperaturas de superfície obtidos pelo produto do sensor MODIS MOD11A2 num período temporal de 17 anos (2000-2016). Nos mapas de temperatura de superfície as temperaturas mínimas no Polo variaram entre $22^{\circ}$ e $24,4^{\circ} \mathrm{C}$ e as máximas de $37^{\circ}$ e $41,1^{\circ} \mathrm{C}$ durante o período analisado (2000- 
2016). O Índice Topográfico de Umidade notou-se que o mesmo apresentou variações de $-4,2$ a 15,9 (Figura 2) sendo que nas áreas mais elevadas os valores foram de -4,2 a 9,9 e nas áreas mais baixas do relevo os valores foram de 13,4 a 15,9 .

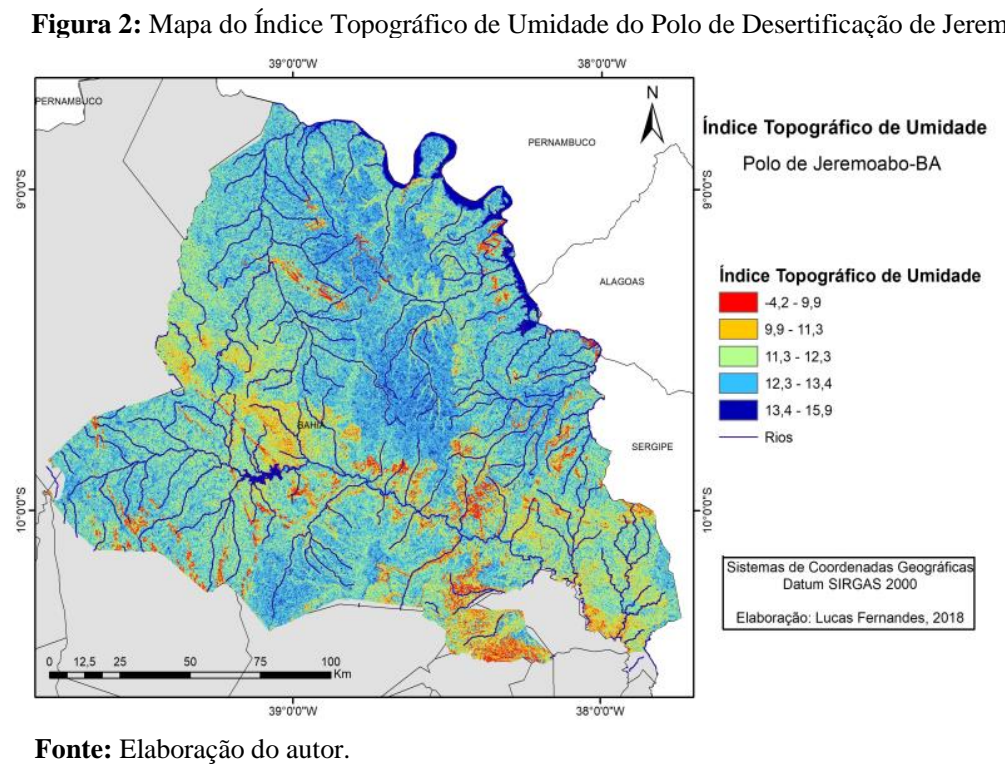

Os valores mais baixos registrados no TWI próximos de $-4,2$ correspondem às áreas do relevo menos propício a saturação hídrica, pois apresentam declividade elevada e áreas de contribuição reduzida, ou seja, o teor de água no solo é baixo. Entretanto, os valores registrados próximos de 15,9 correspondem ao relevo cuja área de contribuição da montante é maior e a declividade é mais suavizada, proporcionando maior índice de saturação hídrica no solo, seja periódica ou permanente, com elevado teor de água no solo.

A correlação das duas variáveis (Temperatura e Umidade) a partir da correlação de pontos do Pearson, para alguns anos não houve correlação para os anos de 2000, 2003, 2006, 2011, 2014 e 2015. Os demais, 2001, 2002, 2004, 2005, 2007, 2008, 2009, 2010, 2012, 2013 e 2016 apresentaram fraca correlação entre as variáveis. Pode-se inferir que não houve correlação entre as duas variáveis a partir dos valores obtidos do Pearson, podendo-se afirmar que as variáveis correlacionadas não dependem linearmente uma da outra, pressupondo-se que uma das variáveis não é contínua.

\section{CONSIDERAÇÕES FINAIS}

O processo da desertificação e suas consequências estão associados aos diversos indicadores ambientais, tendo como destaque as ações antrópicas, ocasionando a degradação do ambiente, especificamente dos solos. Na presente pesquisa foram utilizados apenas dois indicadores para análise da desertificação, a temperatura de superfície e a umidade.

Com a correlação das duas variáveis notou-se que as mesmas não apresentaram correlação ou apresentaram correlação fraca, pois seus valores não tiveram linearidade tendo temperaturas elevadas com baixo e alto índice de umidade, e vice-versa. O resultado baixo da correlação pode estar associado ao fato dos dados utilizados na pesquisa apresentarem resoluções espaciais diferentes, (pixel de $1 \mathrm{~km}$ para os dados de Temperatura e pixel de $30 \mathrm{~m}$ para o TWI). 


\section{REFERÊNCIAS}

ANGELINI, L. P. et al. Relação entre albedo e temperatura da superfície estimados por sensoriamento remoto na área urbana de Cuiabá, Mato Grosso. In: SIMPÓSIO BRASILEIRO DE SENSORIAMENTO REMOTO, 17, 2015, João Pessoa. Anais... Cuiabá: INPE, 2015. p. 1892-1898.

CHARRUA, H. C. C. Desertificação e Reversibilidade dos Problemas de Desertificação. 2014. 143 f. Dissertação (Mestrado) - Universidade de Lisboa, Lisboa, 2014.

COELHO, A. L. N.; CORREA, W. de S. C. Temperatura de Superfície Celsius do Sensor Tirs/Landsat-8: metodologia e aplicações. Revista Geográfica Acadêmica, Boa Vista/RR, v. 7, n. 1, p. 31-45, dez. 2013.

HANCOCK, G. R.; Murphy, D.; Evans, K. G., 2010. Hillslope and catchment scale soil organic carbon concentration: An assessment of the role of geomorphology and soil erosion in an undisturbed environment. Geoderma, v.155, n.36-45.

SANTOS, N. B. F. dos. Distribuições espaciais e temporais de temperaturas de superfície no bioma cerrado: Uma análise integrada a partir de dados orbitais de resolução moderada. 2010. 102 f. Tese (Doutorado) - Curso de Geografia, Universidade Federal de Goiás, Goiânia, 2010. 